\title{
The expression and the functional roles of tissue factor and protease-activated receptor- 2 on SW620 cells
}

\author{
HONG ZHOU ${ }^{1}$, HONGXIN HU ${ }^{1}$, WENXIA SHI ${ }^{1}$, SHUCAI LING ${ }^{2}$, \\ TING WANG ${ }^{1}$ and HAIBO WANG ${ }^{1}$ \\ ${ }^{1}$ Department of Clinical Laboratory and Hematology, Jiangsu University, 301 Xuefu Road, \\ Zhenjiang, Jiangsu 212013, ${ }^{2}$ Department of Anatomy, Zhejiang University School \\ of Medicine, 388 Yuhangtang Road, Hangzhou, Zhejiang 310031, P.R. China
}

Received April 23, 2008; Accepted June 13, 2008

DOI: 10.3892/or_00000111

\begin{abstract}
Tissue factor (TF) is believed to play an important role in tissue repair, inflammation, angiogenesis, and tumor metastasis. Protease-activated receptors (PARs) are widely expressed on various cells including tumor cells and associated with many pathological mechanisms. In the present study, the expression of TF and PAR1, PAR2 on human colon cancer cells (SW620 and SW480) was investigated and their functional roles on the behavior of tumor cells were evaluated. It was demonstrated that SW620 and SW480 cells expressed TF at antigen, activity and mRNA levels. However, the highly metastatic cell line SW620 showed slightly higher TF expression than the low metastatic cell line SW480. The PAR2 antigen was strongly expressed on the membrane of SW620 cells, but not on SW480 cells. The PAR1 antigen was not observed in SW620 or SW480 cells, while PAR1 and PAR2 mRNA was detected in SW620 and SW480 cells. The migratory potential of SW620 was stronger than that of SW480 seen in Boyden chambers. PAR2 agonist (SLIGKV-NH2) and factor VIIa significantly stimulated SW620 cell proliferation, migratory activity, and interleukin 8 (IL-8) secretion compared to control. The stimulating effects of factor VIIa could be inhibited by antiTF and anti-PAR2 but not anti-PAR 1 antibodies. In summary, this study demonstrates that TF and PAR2 are strongly expressed on highly metastatic colonic tumor cells and are closely associated with the proliferation and migration of the cells. TF may elucidate its roles in colonic cancer invasion and metastasis via PAR2 pathway.
\end{abstract}

Correspondence to: Dr Hong Zhou, Department of Clinical Laboratory and Hematology, Jiangsu University, 301 Xuefu Road, Zhenjiang, Jiangsu 212013, P.R. China

E-mail: hongzhou@ujs.edu.cn

Key words: tissue factor, protease-activated receptors, colonic cancer cells, migration

\section{Introduction}

In malignant behavior cancer cells invade and migrate via the blood and lymphatic vessels to form metastatic tumors. The progression of the metastatic state is driven by a great number of somatic mutations, resulting in a tumor cell that differs in several properties from its progenitors (1). The association of coagulant factors and cancer behavior is recognized by many investigators (2). One of the coagulant molecules implicated in the metastatic process is tissue factor (TF), a transmembrane protein that can form a complex with factor VII/VIIa to initiate blood coagulation (3). It was reported that TF could be expressed in a wide variety of malignancies (4). The metastatic melanoma cells expressed higher levels of TF than the nonmetastatic cells (5), and a metastatic rectal carcinoma subline showed enhanced TF expression in comparison to its parental line (6). Transfection of TF promoted metastasis of the melanoma in a mouse model (7), and enhanced primary tumor growth in a pancreatic adenocarcinoma cell line (8). Thus, TF not only contributes to the development of a hyper-coagulable state in cancer patients but also modulates the biological behavior of cancer cells.

Protease-activated receptors (PARs) have recently attracted increasing attention in relation to certain proteases. PARs are members of a group of seven transmembrane $G$ proteincoupled receptors and are activated by the proteolytic cleavage of their amino terminal domain. On the activation of PARs, proteases such as thrombin and trypsin cleave at a point within the extracellular $\mathrm{N}$-terminal domain and, thereby, unmask a new amino terminus that functions as a tethered ligand to bind back to the receptor $(9,10)$. To date, four PARs have been discovered and characterized. PAR1, PAR3, and PAR4 are activated by thrombin, whereas PAR2 is activated by various proteases but not thrombin. Experimentally, PARs can also be activated by synthetic peptides (agonist peptides, AP) that mimic the neo-amino terminus of the cleaved receptors. Interestingly, recent findings that PAR2 is activated by various proteases such as trypsin, mast cell tryptase, neutrophil serine proteases, the cell membrane-anchored membrane-type serine protease 1 , factor Xa, and TF/VIIa complex (11-13) imply its pleiotropic physiological roles. 
Growing evidence suggests that PAR1 and PAR2 may play a role in the setting of cancer growth and metastasis (14). In addition, it was observed that TF elicited its function on tumor metastasis relating to PARs. TF/VIIa complex activated PAR2 and thereby regulated proangiogenic growth factor expression as well as integrins involving crosstalk with the TF cytoplasmic domain (15). It was also suggested that PAR1 in tumor metastasis was promoted by TF (16). However, the mechanism by which TF and PARs contribute to tumor cell invasion and metastasis remains largely unknown. Especially, the functional importance of PAR2 in human colonic cancer cells is poorly understood.

Similar to the correlation between TF and PAR expression and metastatic potential, interleukin-8 (IL-8), originally discovered as a chemotactic factor for leukocytes, has recently been shown to be expressed in many tumor cells and contributing to human cancer progression (17). It has been reported that $\mathrm{TF} / \mathrm{VII}$ a could up-regulate IL-8 expression in a breast carcinoma cell line, MDA-MB-231, mediated by PAR2 and stimulate cell migration (18). In the current study, the expression of TF and PAR1, PAR2 on colon cancer cell lines SW620 and SW480 was investigated and their functional roles on tumor cells were evaluated. The correlation of TF and PAR1, PAR2 on the migration of the tumor cells was analyzed. The study demonstrated that TF and PAR2 were strongly expressed on highly metastatic potential colonic tumor cells and were closely associated with the biological behavior of the cells. There was a close correlation between TF/VIIa and PAR2 in colon cancer cells, TF may elucidate its roles in cell invasion and metastasis via PAR2 pathway.

\section{Materials and methods}

Materials. Dulbecco's modified Eagle's medium (DMEM), fetal bovine serum (FBS), trypsin-EDTA (ethylenediamine tetraacetic acid) and penicillin-streptomycin were obtained from Gibco BRL (Grand Island, NY, USA). Monoclonal anti-PAR1 and anti-PAR2 antibodies were purchased from ZYMED Laboratories (South San Francisco, CA, USA). PAR1 agonist SFLLRN-NH2, PAR2 agonist SLIGKV-NH2 and antagonist VKGILS-NH2 were synthesized by Proteintech Group Inc. (Wuhan, P.R. China). The TF ELISA and Activity kits and monoclonal anti-TF antibody were provided by American Diagnostica Inc (Greenwich, CT, USA). Recombinant human factor VIIa was obtained from Novo Nordisk (Maaloev, Denmark). [3H]-TdR was from A-energy Research Institute of China (Bejing, P.R. China). Boyden transwell chambers were purchased from Corning Inc. (Corning, NY, USA). TRIzol and RT-PCR reagents were from Invitrogen (Carlsbad, CA, USA). All other chemicals and reagents used were of the best quality commercially available.

Cell lines and culture. The human colon cancer cell lines SW620 (highly metastatic) and SW480 (low metastatic) were obtained from Shanghai Institutes Biological Sciences (Shanghai, P.R. China). Cells were maintained in DMEM with low-glucose medium supple-mented with $1 \%$ glutamine, $1 \%$ penicillin/streptomycin, and $10 \%$ FBS. The cells were cultured at $37^{\circ} \mathrm{C}$ and $5 \% \mathrm{CO}_{2}$ in a humidified incubator to near confluence and were deprived of serum for $16 \mathrm{~h}$ before they were stimulated with agonists or other reagents.

TF antigen and activity measurement. Cells were briefly trypsinized, suspended in DMEM/10\% FBS, pelleted, and resuspended in Tris-buffered saline (TBS) at a density of $10^{6}$ cells per $\mathrm{ml}$, pelleted again, and lysated with $1 \mathrm{ml}$ of lysate buffer (TBS/1\% triton 100/1 mM PMSF). The cell TF antigen level was determined using IMUBIND ${ }^{\circledR}$ tissue factor ELISA kit (ADI, USA) according to the manufacturer's instructions. The TF activity was measured as factor $\mathrm{X}$ activation by factor $\mathrm{TF} / \mathrm{VII}_{\mathrm{a}}$ complex and the generated factor $\mathrm{X}_{\mathrm{a}}$ was determined using a chromogenic assay (Actichrome ${ }^{\circledR} \mathrm{TF}$ provided by $\mathrm{ADI}$ ). The TF antigen and activity were expressed as $\mathrm{pg} / \mathrm{ml}$ and $\mathrm{pM}$ respectively.

Immunocytochemistry assay. The expression of PAR1 and PAR2 on SW620 and SW480 cells was investigated by immunocytochemistry methods. The cells were cultured and confluent on the glass slide, fixed with $4 \%$ paraformaldehyde, incubated with the monoclonal mouse anti-human PAR1 or PAR2 antibodies (1:1000) in $10 \mathrm{mM} \mathrm{PBS/0.5 \%} \mathrm{Triton} \mathrm{X-100/}$ $5 \% \mathrm{FBS}$ at $4^{\circ} \mathrm{C}$ for $72 \mathrm{~h}$. After being washed 3 times, the smears were treated with biotin-labeled goat anti-mouse antibody $(1: 200)$ at $4^{\circ} \mathrm{C}$ for $48 \mathrm{~h}$. Following washes, the slides were treated with $\mathrm{ABC}$ solutions for $24 \mathrm{~h}$ at $4^{\circ} \mathrm{C}$. Finally, the slides were chromogenized by $0.05 \%$ DAB $/ 0.01 \%$ $\mathrm{H}_{2} \mathrm{O}_{2}$. The immune-specific reaction was shown by brown color on the surface of the cells.

$R T$-PCR analysis. Total cellular RNA was extracted from the cells using TRIzol according to the manufacturer's instructions. Oligo dT-primed reverse transcription was performed in $2 \mu \mathrm{g}$ of total RNA in a $25 \mu \mathrm{l}$ reaction volume (Applied Biosystems, 2720 Thermal Cycler, USA). The primes used for PCR were as follows: TF forward: 5'TCAGGTGATCCACCCACCTT-3' and the reverse: 5'GCACCCAATTTCCTTCCATTT-3'. PAR1 forward: 5'-CCC GCAGGCCAGAATCAAA-3', reverse: 5'-AAAGGGGAG CACAGACACAAACAG-3', PAR2 forward: 5'-CTACTC AGATGACCCCAGAAACT-3', reverse: 5'-CCCAAA GTGCTAGGATTACAGG-3'. The control housekeeping gene GAPDH forward: 5'-GGATTTGGTCGTATTGGG-3', reverse: 5'-GGAAGATGGTGATGGGATT-3'. The primes were constructed to generate fragment of $140 \mathrm{bp}$ for TF, 395 bp for PAR1, 399 bp for PAR2, 205 bp for GAPDH. Cycling conditions were as follows: $94^{\circ} \mathrm{C}$ for $30 \mathrm{sec}, 60^{\circ} \mathrm{C}$ for $30 \mathrm{sec}$ and $72^{\circ} \mathrm{C}$ for $30 \mathrm{sec}$ for 35 cycles. Amplifies samples were visualized on $2 \%$ agarose gel stained with ethidium bromide and photographed under UV light.

Cell migratory assay. Cell migration assays were performed using modified Boyden chambers with a $6.5 \mu \mathrm{m}$ diameter, porous $(8 \mu \mathrm{m})$ polycarbonate membrane separating the two chambers (Transwell, Corning Inc.). Cells were harvested by briefly exposure to trypsin/EDTA and neutralized with DMEM medium. Cells were washed and resuspended in DMEM with $0.1 \%$ bovine serum albumin (BSA) in an adequate concentration. When indicated, cells $\left(1.0 \times 10^{5}\right.$ in $100 \mu \mathrm{l})$ were incubated with $10 \mu \mathrm{g} / \mathrm{ml}$ of anti-TF, or anti- 
PAR1, or anti-PAR2 antibodies for $60 \mathrm{~min}$ at $37^{\circ} \mathrm{C}$, then placed in the upper compartments. When function-blocking antibodies were tested, antibodies were also present at the indicated concentration in the lower compartments. Cells were placed in the upper compartment of the migration chamber with $10 \mathrm{nM}$ of factor VIIa, or $100 \mu \mathrm{M}$ of PAR1agonist, or PAR2-agonist, or PAR2-antagonist in upper and lower com-partments. Cells were allowed to migrate for $18 \mathrm{~h}$ at $37^{\circ} \mathrm{C}$ in $5 \% \mathrm{CO}_{2}$. Cells without any agonists or inhibitors in the assay were used as control. At the end of the assay, the upper surface of the membrane was wiped with a cotton tip applicator to remove non-migratory cells. Cells that have migrated through pores to the lower side of membrane were fixed, stained and counted by light microscopy under high power field $(\mathrm{x} 400)$. For each triplicate, the number of cells in ten high power fields was determined and the counts were averaged.

Cell proliferation. The growth and proliferation of the cells under different conditions were measured using [3H]-TdR incorporation method. Briefly, cells were incubated with $10 \mu \mathrm{g} /$ $\mathrm{ml}$ of anti-TF, or anti-PAR1, or anti-PAR2 antibodies for $60 \mathrm{~min}$ at $37^{\circ} \mathrm{C}$, then stimulated with $10 \mathrm{nM}$ of factor VIIa, or $100 \mu \mathrm{M}$ of PAR1-agonist, or PAR2-agonist, or PAR2antagonist. After growing to $80 \%$ of confluence, the cells were incubated with $1 \mu \mathrm{Ci} / \mathrm{ml}$ of [3H]-TdR for $18 \mathrm{~h}$. Cells were washed and harvested, then the [3H]-TdR incorporation measured by scintillation counting (LS6500, Multi-Purpose Scintillation Counter, Beckman, USA).

IL-8 level measurement. IL-8 protein level in conditioned media from SW620 cells that were exposed to VIIa, PAR1 and PAR2 agonists as well as other materials (similar to above described treatment) for $18 \mathrm{~h}$ was measured using the IL-8 ELISA kit from R\&D Systems Inc. (MN, USA) according to the manufacturer's instructions.

Statistical analysis. Data are shown as the mean \pm standard error of the mean (SEM) of triplicate determinations calculated using GraphPad Prism 3.0 software (GraphPad Software, Inc., San Diego, CA).

\section{Results}

TF expression on SW620 and SW480 cells. ELISA assays were used to evaluate TF antigen level of the cell lysates. The TF activity was investigated by measuring factor VIIadependent generation of factor $\mathrm{Xa}$, using a chromogenic substrate. The TF mRNA expression was evaluated by RTPCR. As shown in Fig. 1, high and low metastatic cells, SW620 and SW480 cells, strongly expressed TF at antigen, activity and mRNA levels. It appeared that TF antigen, activity and mRNA level of SW620 cells were higher than that of SW480 cells, but no significant statistical difference was seen.

PAR1 and PAR2 expression on SW620 and SW480 cells. Immunocytochemistry analysis revealed that PAR2 antigen was strongly expressed on the surface membrane of SW620 cells (Fig. 2D), but not on SW480 cells (Fig. 2C). The PAR1
A.

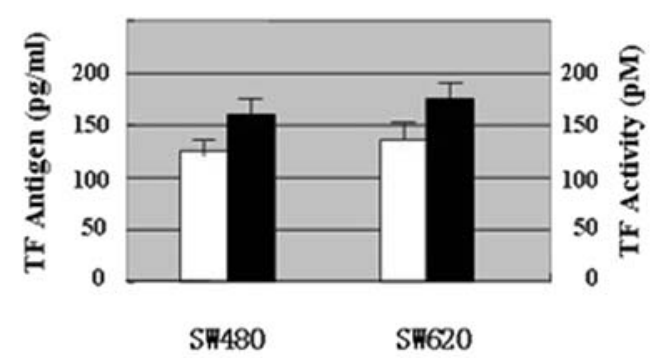

B.

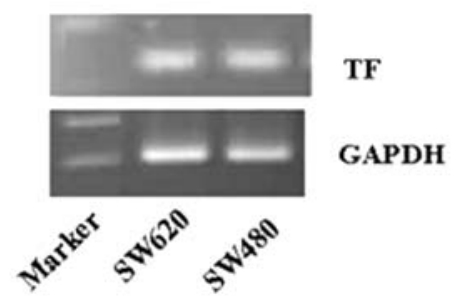

Figure 1. TF expression on colon cancer cell lines. SW620 and SW480 cells $\left(1 \times 10^{6}\right)$ were collected and lysated, the TF antigen and activity were measured as described in Materials and methods. The TF mRNA level was detected using RT-PCR. A, TF antigen level (pg/ml) and activity (pM); B, TF mRNA expression. Data shown are the mean \pm SEM of triplicate determinations.

antigen was not observed in SW620 cells, neither in SW480 cells (Fig. 2B and A), while PAR1 and PAR2 mRNA expression were detected in SW620 and SW480 cells. It appears that SW620 cells contained higher level of PAR1 and PAR2 mRNA than SW480 cells, but no significant statistical difference was seen (Fig. 3).

The effects of TF and PAR1, PAR2 on SW620 cell migration. The migratory assays showed greater number of SW620 cells migrating across the membrane in Boyden chambers than that of SW480 cells without any stimulant (data not shown). Therefore, further experiments were mainly focused on SW620 cells. To test whether TF, PAR1 and PAR2 expressed on colon cancer cells are associated with cell metastasis, we used different stimulants or blocking antibodies of TF, PAR1 and PAR2 in the cell migratory assays. Fig. 4A mainly showed the effects of TF/VIIa complex on SW620 cell migration. VIIa significantly enhanced SW620 cell migration compared to media control $(\mathrm{P}<0.01)$. The effects of VIIa were partly inhibited by antiTF $(\alpha-\mathrm{TF})$, but not by control isotype antibody mopc-21, demonstrating the effects of VIIa were VIIa-TF complex mediated. The antibodies of $\alpha$-TF and mopc- 21 themselves had no effects on cell migration. The effects of PAR1 and PAR2 were seen in Fig. 4B. PAR2 agonist (R2-AP) enhanced SW620 cell migration $(\mathrm{P}<0.01$ vs. control), while PAR1 agonist (R1-AP) had no such stimulatory effect. However, combination of R1-AP and R2-AP strongly increased cell migratory numbers $(\mathrm{P}<0.001$ vs. control). PAR2 antagonist (R2-anta) did not affect cell migration. The 


\section{A. $\mathbf{S W 4 8 0} / \boldsymbol{\alpha}-\mathrm{R} \mathbf{1}$}

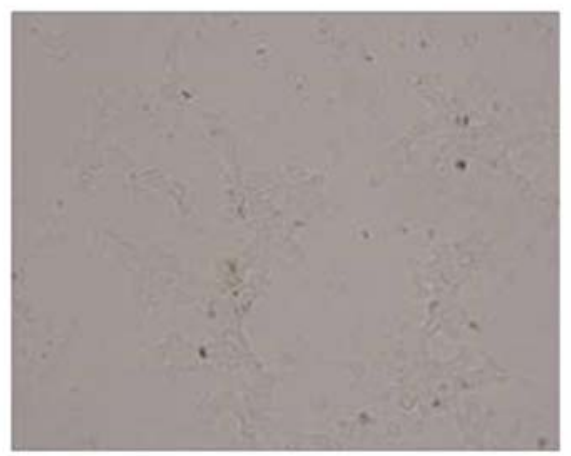

C. $\mathbf{S W 4 8 0} / \boldsymbol{\alpha}-\mathrm{R2}$

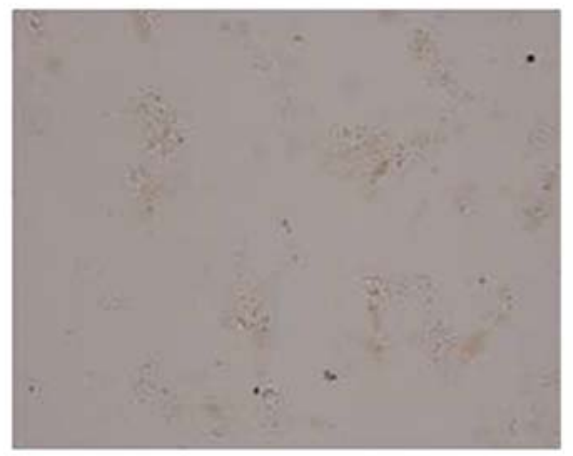

B. $\mathrm{SW620} / \boldsymbol{\alpha}-\mathrm{R} 1$

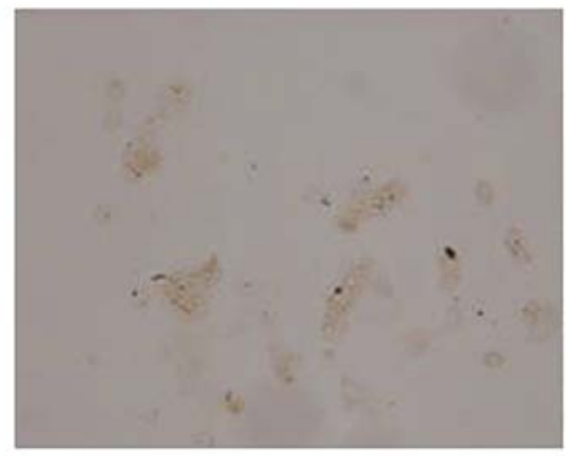

D. $\mathrm{SW620} / \boldsymbol{\alpha}-\mathrm{R} 2$

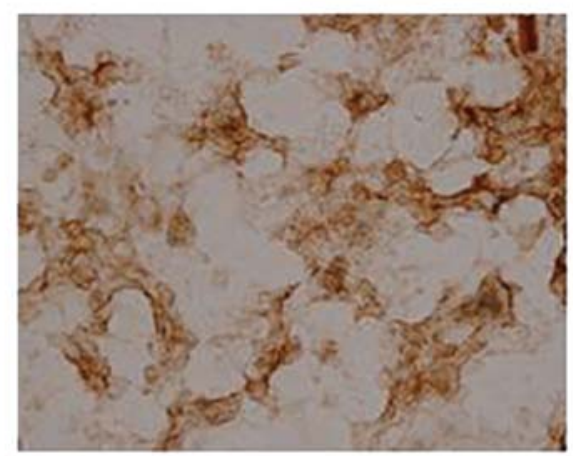

Figure 2. PAR1 and PAR2 antigen level on SW620 and SW480 cells detected by immunocytochemistry using monoclonal antibodies. A and C, SW480 cells; B and D, SW620 cells; A and B, reaction with anti-PAR1 antibody ( $\alpha-R 1)$; C and D, reaction with anti-PAR2 antibody ( $\alpha$-R2). The pictures were taken under light microscopy with high power field (x400).

A.
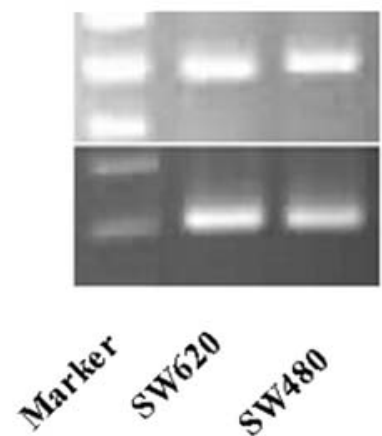

B.
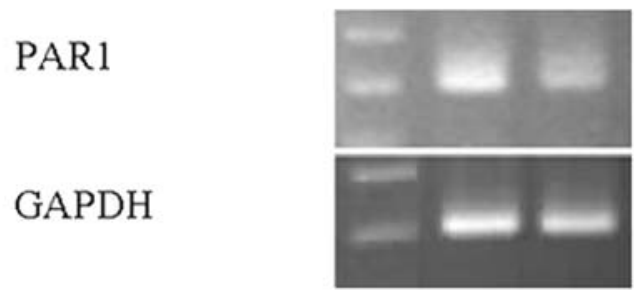

PAR2

GAPDH

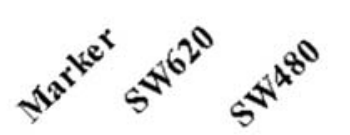

Figure 3. PAR1 and PAR2 mRNA expression on SW620 and SW480 cells investigated by RT-PCR. Total cellular RNA was extracted from the cells $\left(1 \times 10^{6}\right)$ and RT-PCR was carried out using PAR1, PAR2 primes respectively. The RT-PCR products were visualized on $2 \%$ agarose gel stained with ethidium bromide and photographed under UV light.

stimulating effects of R2-AP were inhibited by anti-PAR2 $(\alpha-$ R2) antibody. Interestingly, the effects of VIIa could be decreased by $\alpha$-R2 and R2-anta, but not by anti-PAR1 ( $\alpha-\mathrm{R} 1)$ (Fig. 4C), indicating some correlation of TF/VIIa and PAR2 on cell migration.
The effects of TF and PAR1, PAR2 on SW620 cell proliferation. Furthermore, the cell growth and proliferation ability was evaluated with different stimulants or inhibitors of TF, PAR1 and PAR2. The data showed that factor VIIa could strongly stimulate SW620 cell proliferation $(\mathrm{P}<0.001$ vs. control), $\alpha-\mathrm{TF}$ inhibited the effects of VIIa (Fig. 5A). R2- 
A.

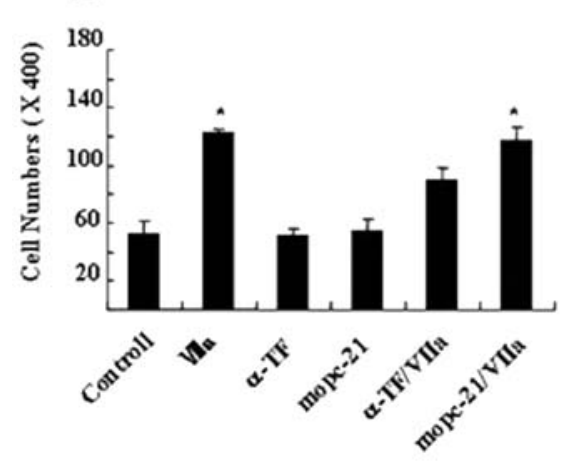

B.

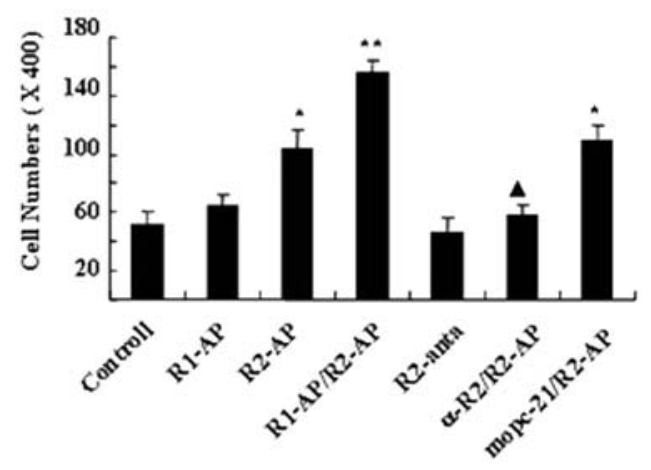

C.

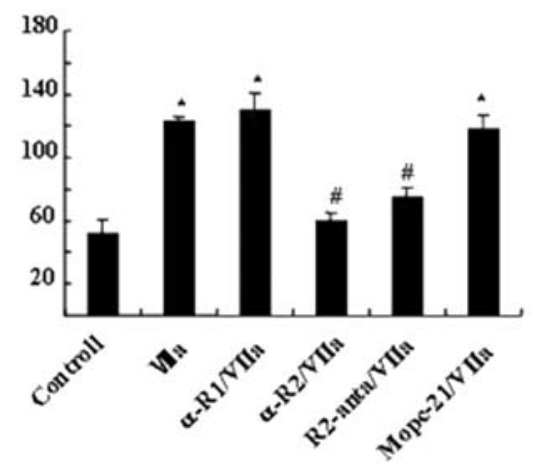

Figure 4. SW620 cell migratory potential measured by modified Boyden chambers. The cells were treated with different agents and the migration assay was carried out as described in Materials and methods. A, The effects of TF/VIIa; B, The effects of PAR1 and PAR2; C, The correlation of TF/VIIa and PAR2. Cells without any agent were used as a control; VIIa, activated factor VII (10 nM); $\alpha$-TF, anti-TF antibody; $\alpha$-R1 and $\alpha$-R2, antiPAR1 and anti-PAR2 antibodies; mopc-21, isotype control antibody (all the antibodies are monoclonal mouse anti-human, $10 \mu \mathrm{g} / \mathrm{ml}$ ); R2-anta, PAR2 antagonist (100 $\mu \mathrm{M})$; R1-AP and R2-AP, PAR1 and PAR2 agonists (100 $\mu \mathrm{M})$. Data shown are the mean \pm SEM of ten fields of triplicate determinations. ${ }^{*} \mathrm{P}<0.01$ vs. control; ${ }^{* *} \mathrm{P}<0.001$ vs. control; $\triangle \mathrm{P}<0.01$ vs. $\mathrm{R} 2-\mathrm{AP}$ alone and ${ }^{\text {"}} \mathrm{P}<0.01$ vs. VIIa alone.

AP significantly enhanced cell proliferation $(\mathrm{P}<0.01)$ and could be inhibited by $\alpha-\mathrm{R} 2$. Combination of R1-AP and R2AP had no more superimposed effects, even though R1-AP alone had slightly enhancing effect to cell proliferation (Fig. 5B). Similarly, the effects of VIIa on cell proliferation could be decreased by $\alpha-\mathrm{R} 2$ and R2-anta, but not by $\alpha-\mathrm{R} 1$, further demonstrating the interaction of TF/VIIa and PAR2 (Fig. 5C).

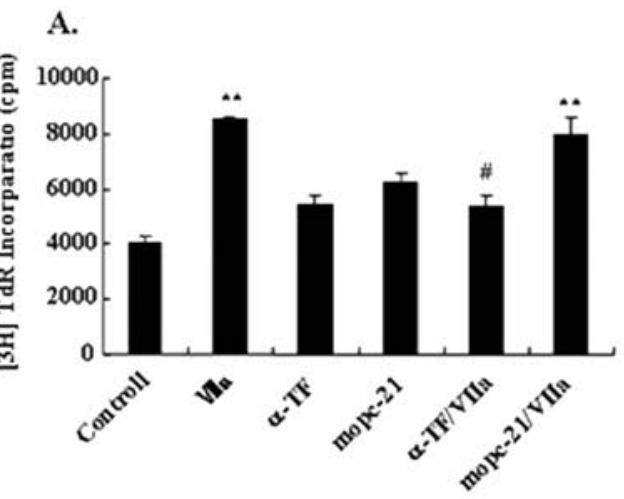

B.
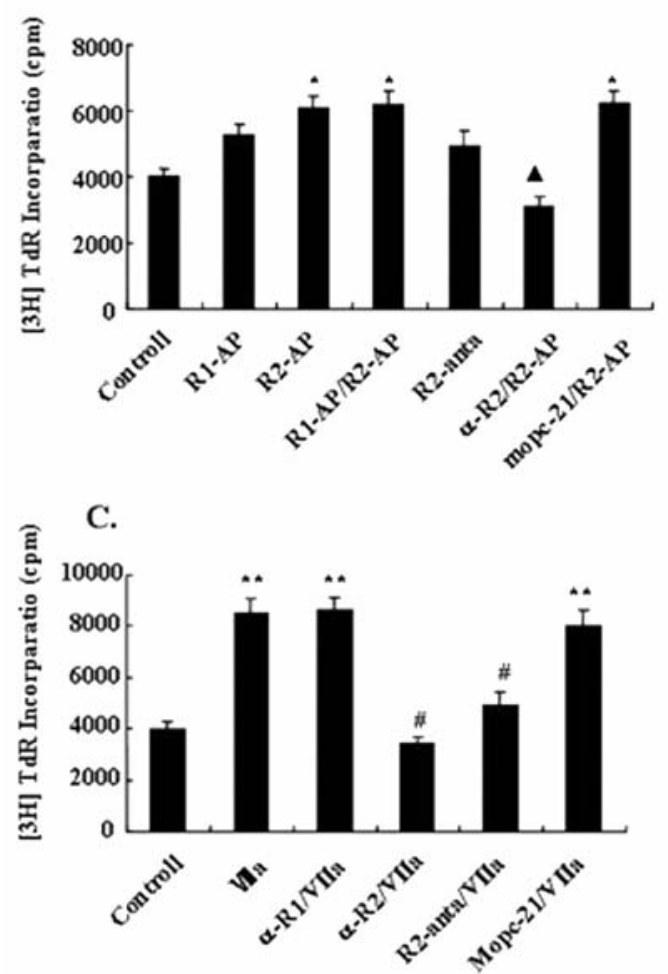

Figure 5. SW620 cell proliferation potential detected using [3H]-TdR incorporation. The cells were treated with different agents and the proliferation potential was investigated by $[3 \mathrm{H}]-\mathrm{TdR}$ incorporation. A, The effects of TF/VIIa; B, The effects of PAR1 and PAR2; C, The correlation of TF/VIIa and PAR2. Cells without any agent were used as a control. All the concentration of materials was similar to that in Fig. 4. Data shown are the mean \pm SEM of triplicate determinations. ${ }^{*} \mathrm{P}<0.01$ vs. control; ${ }^{*} \mathrm{P}<0.001$ vs control; $\triangle \mathrm{P}<0.01$ vs. $\mathrm{R} 2-\mathrm{AP}$ alone and ${ }^{\#} \mathrm{P}<0.01$ vs. VIIa alone.

The effects of TF and PAR1, PAR2 on IL-8 expression. In addition, IL- 8 protein secreted by SW620 cells was investigated by treatment with VIIa, PAR1 and PAR2 agonists as well as other materials. The data are shown in Fig. 6A, B and C. VIIa and R2-AP significantly increased IL-8 protein level secreted by SW620 cell $(\mathrm{P}<0.01$ vs. control). R1-AP had slight stimulating effect, but had no significant statistical difference compared to control. $\alpha-\mathrm{R} 2$ inhibited not only the effects of R2-AP, but also that of VIIa. These data suggested that the stimulating effects of VIIa and PAR2 on SW620 cell proliferation and migration were associated with enhanced IL-8 expression. 
A.

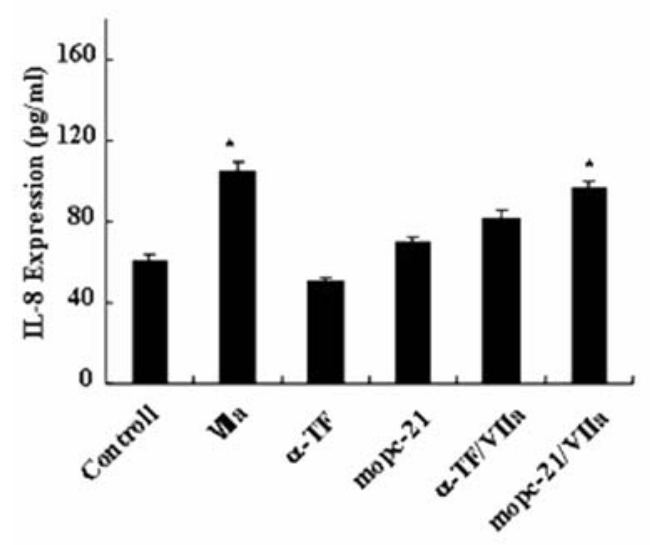

B.

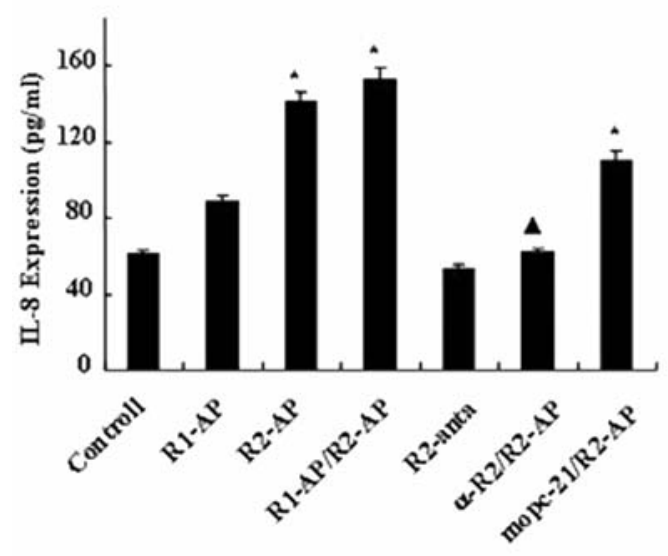

C.

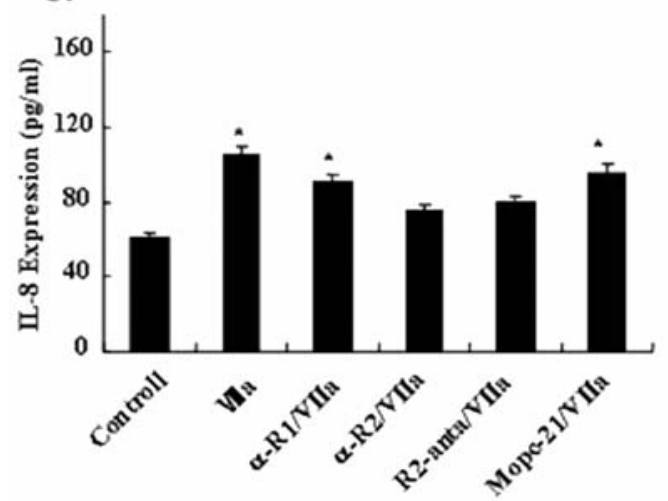

Figure 6. IL-8 secretion by SW620 cells treated with various materials. The cells were treated with materials similar to that of migratory assay and IL-8 protein level in conditioned media was detected using the IL-8 ELISA kit. A, The effects of TF/VIIa; B, The effects of PAR1 and PAR2; C, The correlation of TF/VIIa and PAR2. Cells without any agent were used as a control. Data shown are the mean \pm SEM of triplicate determinations. ${ }^{*} \mathrm{P}<0.01$ vs. control; ${ }^{\wedge} \mathrm{P}<0.01$ vs. R2-AP alone.

\section{Discussion}

$\mathrm{TF}$ is the best known primary cellular initiator of blood coagulation. After vessel injury, the TF/VIIa complex activates the coagulation protease cascade, which leads to fibrin deposition and activation of platelets. TF deficiency causes embryonic lethality in the mouse, but there have been no studies of TF deficiency in humans. These results indicate that
TF is essential for life, most likely because of its central role in hemostasis. Recent studies have revealed a non-hemostatic role of TF in the generation of coagulation proteases and subsequent activation of PARs on vascular cells (19). This TF-dependent signalling contributes to a variety of biological processes, including inflammation, angiogenesis, metastasis, and cell migration $(20,21)$. A great number of studies indicate that TF expressed on many types of cancer cells are linked to the genetic status of the cells and may serve as a useful prognostic factor of recurrence in tumor patients (22-24). In this study, TF expression at antigen, activity and mRNA levels was found in the colon cancer cell lines, SW620 (highly metastatic) and SW480 (low metastatic). SW620 cells had higher level of TF than SW480 cells (although not statistically significant). Also SW620 cells possessed stronger migratory ability than SW480 cells in Boyden chamber assays. Factor VIIa markedly enhanced SW620 cell migration and proliferation as well as IL-8 secretion. These results demonstrate that $\mathrm{TF}$ overexpression is closely associated with tumor growth, invasion and metastasis, being closely coincident with many previous studies (19-24).

On the other hand, the presence of PARs and their activating proteases within the tumor microenvironment (TME) suggests an autocrine and/or paracrine cascade in the processes of cellular metastasis. It was reported that PAR1 and PAR2 protein and mRNA could be expressed in human malignant tumor cells and local mast cells, macrophages, endothelium, and vascular smooth muscle cells of the TME and contribute to tumor cell motility and metastasis (25). Actually, there are different opinions on PAR1 and PAR2 expression with cancer cell invasion and metastasis to date. Some studies suggest a direct correlation between the levels of PAR1 expression and the invasion properties of breast carcinomas. PAR1 induces angiogenesis in animal models in vivo and exhibits an oncogenic phenotype of enhanced ductal complexity when overexpressed in mouse mammary glands (26). While other studies demonstrate that the PAR2 expression on some tumors is related to the cell proliferation, motility and invasion (27). In our data, the highly metastatic potential SW620 cells strongly expressed PAR2 at protein and mRNA levels, although having PAR1 mRNA not protein expression. The low metastatic potential SW480 cells expressed PAR1 and PAR2 only at mRNA levels, no obvious protein display. These results are somewhat different from the study of Darmoul et al, which indicated that PAR1 aberrant expression and activation could induce human colon cancer cell proliferation and motility (28). Our data indicate that PAR2 is more closely related to colon cancer metastasis. It appears that PAR1 and PAR2 are important for cancer cell biological behavior, possibly depending on the type of cancers and stimulants. Also, there are some PAR signalling dysregulation in cancer (29).

Growing evidence suggests that TF and factor VIIa in the oncogenic process are through the activation of signal transduction pathways via the proteolytic cleavage of PARs (3). It was found that PAR2 had a critical role in cancer cell migration and invasion and functions as the endogenous receptor for coagulant proteases VIIa and Xa in cancer cells (30). In tumor cells, TF/VIIa activated PAR2 and thereby 
regulated proangiogenic growth factor expression as well as integrins involving crosstalk with the TF cytoplasmic domain. $\mathrm{TF} / \mathrm{VIIa}$-mediated signalling in human breast cancer cells occured most efficiently by formation of the TF-VIIa-FXa complex. One of the physiological consequences of this signalling pathway was enhanced cell migration that was probably mediated by PAR2, but not PAR1 activation (31). It was also demonstrated that overexpression of PAR 1 in melanoma cells enhanced the metastatic potential of cells with high TF expression, indicating a possible synergy between TF and PAR1 in promoting metastasis (16). In our data, SW620 cells overexpressed TF and PAR2 at protein and mRNA levels, no obvious PAR1 protein was observed. Factor VIIa and PAR2 agonist significantly enhanced cell migration and proliferation and IL-8 secretion. Anti-TF and anti-PAR2 but not anti-PAR1 antibodies, as well as PAR2 antagonist inhibited the effects of FVIIa. These results strongly suggested that TF-VIIa-PAR2 signal pathway was more important for colon cancer biological behaviors, especially for tumor metastasis. Interestingly, PAR1 agonist alone had a slight effect on cell proliferation and migration, but combination of PAR 1 and PAR2 agonists remarkly increased cell migratory ability, indicating some crossreaction between the PARs.

It is now suggested that TF/VIIa may switch on the different signal pathways following disulfide exchange of TF extracellar domain mediated by protein disulfide isomerase (PDI). Thus, TF/VIIa can facilitate PAR cleavage and activation through coagulant and non-coagulant ways $(32,33)$. Moreover, the lipid raft and caveolae of cell membrane may play a selective role in modulating the TF/VIIa signalling function without affecting the coagulant activity (34).

A number of studies have showed that IL-8 can stimulate cell migration and invasion in a variety of tumor cell types, such as hepatocellular carcinoma cells (35). In this study, IL8 protein expression could be increased by VIIa and PAR2 agonists, implying a correlation between IL-8 expression and colon cancer metastasis.

In conclusion, our results demonstrate the overexpression of TF and PAR2 on highly metastatic colon cancer cells (SW620) and their promoting roles for cell proliferation and motility as well as cytokine (IL-8) secretion. TF-VIIa-PAR2 pathway may be very important for the malignant behavior of colon cancers. Therapeutics that prevent TF-VIIa complex formation and PAR2 activity may be useful for preventing colon tumor growth and dissemination.

\section{Acknowledgements}

This study was in part supported by a grant of National Natural Science Foundation of China (No. 30670907), the National Education Program of China (No. [2003]406) to Hong Zhou.

\section{References}

1. Fidler IJ: Critical factors in the biology of human cancer metastasis: twenty-eighth G.H.A. Clowes memorial award lecture. Cancer Res 50: 6130-6138, 1990.

2. Rickles FR, Patierno S and Fernandez PM: Tissue factor, thrombin, and cancer. Chest 124: S58-S68, 2003.
3. Versteeg HH, Spek CA, Peppelenbosch MP and Richel DJ: Tissue factor and cancer metastasis: the role of intracellular and extracellular signaling pathways. Mol Med 10: 1-6, 2004.

4. Callander NS, Varki N and Rao LV: Immuno-histochemical identification of tissue factor in solid tumors. Cancer 70: 1194-1201, 1992.

5. Mueller BM, Reisfeld RA, Edgington TS and Ruf W: Expression of tissue factor by melanoma cells promotes efficient hematogenous metastasis. Proc Natl Acad Sci USA 89: 11832-11836, 1992.

6. Kataoka H, Uchino H, Asada Y, et al: Analysis of tissue factor and tissue factor pathway inhibitor expression in human colorectal carcinoma cell lines and metastatic sublines to the liver. Int J Cancer 72: 878-884, 1997.

7. Bromberg ME, Konigsberg WH, Madison JF, Pawashet A and Garen A: Tissue factor promotes melanoma metastasis by a pathway independent of blood coagulation. Proc Natl Acad Sci USA 92: 8205-8209, 1995.

8. Kakkar AK, Chinswangwatanakul V, Lemoine NR, Tebbutt S and Williamson RC: Role of tissue factor expression on tumour cell invasion and growth of experimental pancreatic adenocarcinoma. Br J Surg 86: 890-894, 1999.

9. Schmidlin F and Bunnett NW: Protease-activated receptors: how proteases signal to cells. Curr Opin Pharmacol 1: 575-582, 2001.

10. Macfarlane SR, Seatter MJ, Kanke T, Hunter G and Plevin R: Proteinase activated receptors. Pharmacol Rev 53: 245-282, 2001.

11. Uehara A, Muramoto K, Takada H and Sugawara S: Neutrophil serine proteinases activate human nonepithelial cells to produce inflammatory cytokines through protease-activated receptor 2 . J Immunol 170: 5690-5696, 2003.

12. Camerer E, Kataoka H, Kahn M, Lease K and Coughlin SR: Genetic evidence that protease-activated receptors mediate factor Xa signaling in endothelial cells. J Biol Chem 277: 16081-16087, 2002

13. Takeuchi T, Harris JL, Huang W, Yan KW, Coughlin SR and Craik CS: Cellular localization of membrane-type serine protease 1 and identification of protease-activated receptor- 2 and singlechain urokinase-type plasminogen activator as substrates. J Biol Chem 275: 26333-26342, 2000.

14. Massi D, Naldini A, Ardinghi C, et al: Expression of proteaseactivated receptors 1 and 2 in melanocytic nevi and malignant melanoma. Hum Pathol 36: 676-685, 2005.

15. Ahamed J and Ruf W: Protease-activated receptor 2-dependent phosphorylation of the tissue factor cytoplasmic domain. J Biol Chem 279: 23038-23044, 2004.

16. Bromberg ME, Bailly MA and Konigsberg WH: Role of protease-activated receptor 1 in tumor metastasis promoted by tissue factor. Thromb Haemost 86: 1210-1214, 2001.

17. Xie K: Interleukin-8 and human cancer biology. Cytokine Growth Factor Rev 12: 375-391, 2001.

18. Hijortoe GM, Petersen LC, Albrektsen T, et al: Tissue factorfactor VIIa-specific up-regulation of IL-8 expression in MDAMB-231 cells is mediated by PAR-2 and results in increased cell migration. Blood 103: 3029-3037, 2004.

19. Mackman N: Role of tissue factor in hemostasis, thrombosis, and vascular development. Arterioscler Thromb Vasc Biol 24: 1015-1022, 2004.

20. Hembrough TA, Swartz GM, Papathanassiu A, et al: Tissue factor/factor VIIa inhibitors block angiogenesis and tumor growth through a nonhemostatic mechanism. Cancer Res 63: 2997-3000, 2003.

21. Poon RTP, Lau CPY, Ho JWY, Yue WC, Fan ST and Wong J: Tissue factor expression correlates with tumor angiogenesis and invasiveness in Human hepatocellular carcinoma. Clin Cancer Res 9: 5339-5345, 2003.

22. Yu JL, May L, Lhotak V, et al: Oncogenic events regulate tissue factor expression in colorectal cancer cells: implications for tumor progression and angiogenesis. Blood 105: 1734-1741, 2005.

23. Nitori N, Ino Y, Nakanishi Y, et al: Prognostic significance of tissue factor in pancreatic ductal adenocarcinoma. Clin Cancer Res 11: 2531-2539, 2005.

24. Kaido T, Oe H, Yoshikawa A, Mori A, Arii S and Imamura M: Tissue factor is a useful prognostic factor of recurrence in hepatocellular carcinoma in 5-year survivors. Hepatogastroenterology 52: 1383-1387, 2005. 
25. Shi X, Gangadharan B, Brass LF, Ruf W and Mueller BM: Protease-activated receptors (PAR1 and PAR2) contribute to tumor cell motility and metastasis. Mol Cancer Res 2: 395-402, 2004 ,

26. Yin YJ, Salah Z, Granovsky SG, et al: Human proteaseactivated receptor 1 expression in malignant epithelia: a role in invasiveness. Arterioscler Thromb Vasc Biol 23: 940-944, 2003.

27. Ge L, Shenoy SK, Lefkowitz RJ and Fea KD: Constitutive protease-activated receptor-2-mediated migration of MDA MB231 breast cancer cells requires both -Arrestin-1 and -2. J Biol Chem 279: 55419-55424, 2004.

28. Darmoul D, Gratio V, Devaud H, Lehy T and Laburthe M: Aberrant expression and activation of the thrombin receptor protease-activated receptor-1 induces cell proliferation and motility in human colon cancer cells. Am J Pathol 162: 15031513,2003

29. Arora P, Ricks TK and Trejo J: Protease-activated receptor signalling, endocytic sorting and dysregulation in cancer. J Cell Sci 120: 921-928, 2007.

30. Morris DR, Ding Y, Ricks TK, Gullapalli A, Wolfe BL and Trejo J: Protease-activated receptor-2 is essential for factor VIIa and $\mathrm{Xa}$-induced signaling, migration, and invasion of breast cancer cells. Cancer Res 66: 307-314, 2006.
31. Jiang X, Bailly MA, Panetti TS, Cappello M, Konigsberg WH and Bromberg ME: Formation of tissue factor-factor VIIafactor Xa complex promotes cellular signaling and migration of human breast cancer cells. J Thromb Haemost 2: 93-101, 2004.

32. Ahamed J, Versteeg HV, Kerver M, et al: Disulfide isomerization switches tissue factor from coagulation to cell signaling. Proc Natl Acad Sci USA 103: 13932-13937, 2006.

33. Camerer E and Trejo J: Cryptic messages: is noncoagulant tissue factor reserved for cell signaling. Proc Natl Acad Sci USA 103: 14259-14260, 2006.

34. Awasthi V, Mandal SK, Papanna V, Vijaya L, Rao M and Usha R: Modulation of tissue factor-factor VIIa signaling by lipid rafts and caveolae. Arterioscler Thromb Vasc Biol 27: 1447-1455, 2007.

35. Kubo F, Ueno S, Hiwatashi K, et al: Interleukin 8 in human hepatocellular carcinoma correlates with cancer cell invasion of vessels but not with tumor angiogenesis. Ann Surg Oncol 12: 800-807, 2005. 